\title{
ESPR uroradiology task force and ESUR Paediatric Work Group-Imaging recommendations in paediatric uroradiology, part VI: childhood renal biopsy and imaging of neonatal and infant genital tract
}

\author{
Minutes from the task force session at the annual ESPR Meeting 2012 in Athens \\ on childhood renal biopsy and imaging neonatal genitalia
}

\author{
Michael Riccabona • Maria Luisa Lobo • Ulrich Willi • Fred Avni • \\ Beatrice Damasio • Lil-Sofie Ording-Mueller • Johan Blickman • \\ Kassa Darge • Frederika Papadopoulou • Pierre-Hugues Vivier
}

Received: 28 March 2013 /Revised: 22 May 2013 / Accepted: 1 July 2013 / Published online: 20 February 2014

(C) Springer-Verlag Berlin Heidelberg 2014

\begin{abstract}
The European Society of Paediatric Radiology Uroradiology Task Force and the ESUR Paediatric Work Group jointly publish guidelines for paediatric urogenital imaging. Two yet unaddressed topics involving patient safety and imaging load are addressed in this paper: renal biopsy in childhood and imaging of the neonatal genital tract, particularly in girls. Based on our thorough review of literature and variable practice in multiple centers, procedural recommendations are proposed on how to perform renal biopsy in children and how to approach the genital tract in (female) neonates. These are statements by consensus due to lack of sufficient evidence-
\end{abstract}

M. Riccabona $(\bowtie)$

Department of Radiology, Division of Paediatric Radiology,

Medical University and University Hospital LKH Graz,

Auenbruggerplatz 34, A - 8036 Graz, Austria

e-mail: michael.riccabona@klinikum-graz.at

M. L. Lobo

Department of Radiology, Hospital de Santa Maria-CHLN,

University Hospital, Lisbon, Portugal

U. Willi

Department of Radiology, Johns Hopkins University,

Baltimore, MD, USA

F. Avni

Department of Pediatric Radiology, Jeanne de Flandre Hospital, CHRU de Lille, Lille Cedex, France

B. Damasio

Department of Radiology, Gaslini Institute, Genoa, Italy based data. The procedural recommendation on renal biopsy in childhood aims at improving patient safety and reducing the number of unsuccessful passes and/or biopsy-related complications. The recommendation for an imaging algorithm in the assessment of the neonatal genital tract focuses on the potential of ultrasonography to reduce the need for more invasive or radiating imaging, however, with additional fluoroscopy or MRI to be used in selected cases. Adherence to these recommendations will allow comparable data and evidence to be generated for future adaptation of imaging strategies in paediatric uroradiology.

L.-S. Ording-Mueller

Department of Radiology and Nuclear Medicine, Unit for Paediatric Radiology, Oslo University Hospital, Oslo, Norway

J. Blickman

Department of Radiology, University of Rochester, School of Medicine, Rochester, NY, USA

\section{K. Darge}

Department of Radiology, Children's Hospital of Philadelphia,

Philadelphia, PA, USA

F. Papadopoulou

Department of Radiology, Ioannina University Hospital,

Ioannina, Greece

P.-H. Vivier

Hôpital Privé de l'Estuaire, Radiologie,

505 rue Irène Joliot Curie, 76620 Le Havre, France 
Keywords Recommendations · Children · Kidney biopsy · Genital tract malformations

\section{Introduction}

There is a wide variety of pediatric urogenital imaging in different centres. In order to homogenize, ease and improve the specific imaging approach, the ESPR Uroradiology Task Force and the ESUR Paediatric Work Group set out to assess available standards, explore different existing practices, review available literature and jointly draft a proposal for a unified imaging approach. The goal is to standardize imaging at its lowest possible invasiveness by adhering to the ALARA principle to reduce the risk of potential complications and to provide reliable results. The recommendations intend to be comprehensive and to be as basic and practical as possible to encourage their use around the world. This includes the flexibility for adjusting to individual needs and situations ("personalized medicine"). With the given restriction of available evidence from literature, these recommendations are issued as a consensus statement based on thorough review of literature, assessment of the different practices in various centres, and consultation of other related subspecialties dealing with pediatric urogenital conditions.

The group hopes for a wide distribution of and adherence to these new recommendations, which are designed to create comparable data for future meta-analysis and improve evidence level and, thus, uroradiological practice in children.

\section{Renal biopsy in childhood}

Renal biopsies in children are performed by various specialists for different indications and under variable imaging guidance, most commonly using ultrasonography (US). However, in some centers, renal biopsies are performed without any imaging guidance (i.e. blindly). The indication for biopsy is usually defined by the referring paediatric nephrourologist or transplantation specialist. The inherent risks are haemorrhage, injury to the collecting system or arterial-venous fistula (AVF) as potential threats to the kidney. The risk for these complications increases with the number of passes and needle size. While sufficient material must be provided by the procedure to allow for meaningful histology, the amount of renal tissue depends on the suspected condition.

The procedure requires a team-approach by the involved nephrourologist, paediatric anaesthesiologist (analgesia, sedation and monitoring), histopathologist, nurse and/or technician, as well as paediatric and/or interventional radiologist. A standard intervention suite with all necessary equipment and instrumentation available (including monitoring device, oxygen, material for sterile handling, spotlight and microscope) and an open layout is most desirable. Preceding the biopsy, the child's general condition must be assessed as part of a work-up of the nephrourological complaint. In addition, a detailed preinterventional US with colour Doppler sonography (CSD) is indispensable to assess for renal localization and potential risk factors (e.g. duplex kidney with small lower pole system, aberrant vessels, interfering structures, etc.). Preprocedural decision on instrumentation availability and detail is crucial: i.e. size and length of the needle, length of the core cut (which depends on parenchymal thickness), whether coaxial technique is advisable in more difficult access, etc. Patient preparation includes intravenous line, emptied bladder and pre-sedation, as well as a skinnumbing patch or paste administered at the presumed biopsy site. Time-out must be granted to confirm the patient's identity, the indication of the procedure and adequate recent haematological status with regard to bleeding and coagulation, as well as whether informed consent has been obtained.

The child is placed in prone position with adequate ventral support for biopsy of the native kidney. Pre-interventional US is performed for probe positioning and as baseline for postinterventional follow-up. The lower pole of the native left kidney is commonly targeted and the access area is defined by US. In a transplant kidney, the patient is typically supine and a safe needle approach (e.g. from the laterocranial aspect) is selected by US. Local anaesthesia is strongly recommended even with the child in deep sedation. Correct sterile conditions are mandatory for the procedure. Biopsy in younger patients is commonly performed under deep analgo-sedation, administered by the anaesthesiologist. Conscious analgo-sedation may be chosen in older children. Monitoring of blood pressure, heart/respiratory rate and oxygenation is required throughout the procedure. Biopsy should be performed under direct real-time vision and is best with the help of the dedicated needle guide attached to the transducer. The length of the core cut is defined by the thickness of the renal parenchyma (avoid a long cut into narrow parenchyma and injury to the collecting system). Use of an 18-gauge needle is usually adequate for core thickness as well as to minimize the risk of vascular complication. CDS is extremely helpful in avoiding renal vascularity, especially major vessels. Sufficient cortical material, i.e. a sufficient number of glomeruli, is necessary for establishing a diagnosis; medullary tissue is rarely required. Details of specific tissue need to be discussed with the referring nephrologist in advance to select the biopsy area. Commonly, a biopsy gun or a semi-automated biopsy device is used and fired under direct US vision. CDS demonstrates even more conspicuously the risk for potential postbiopsy complications (Table 1). Whether a second pass is necessary for diagnosis needs to be determined by the on-site paediatric nephrologist or histopathologist by evaluating the specimen immediately (preferably under the microscope) for diagnostic adequacy. Upon retrieving the needle, local compression is applied to prevent haemorrhage. For repeat biopsy passes, the biopsy area/needle placement should be changed to minimize the risk of complications or an unsuccessful second pass. 
on the findings and the further management of the patient, a subsequent or final US evaluation may be suggested at 12 and 24 to $48 \mathrm{~h}$ after the procedure, potentially on an outpatient basis. Absence of any major haematoma, haemorrhage, AVF or bladder clot is expected. Withdrawn reno-active antihypertensive drugs may be reinstalled, even if minor haemorrhagic residuals are present. In these conditions, conservative management with repeat monitoring is advised, as most of these findings resolve spontaneously. Severe haemorrhage, large AVF with high shunt flow that endanger renal perfusion and function, or large clots in the collecting system and/or bladder might indicate active treatment, possibly even embolisation of AVF (Table 1).

\section{Imaging the genital tract in the neonate and infant}

To carry out a practical and differentiated imaging approach after birth, a few prerequisites need to be kept in mind. These are:

1. Knowledge of the basic organogenetic facts and fetal development of the urogenital tract.

2. Familiarity with the normal appearance of inner genitalia in neonates and infants, especially in a female (characteristic shape and large size of uterus; frequent presence of even large ovarian follicles).

3. Knowledge of the characteristic morphology in common genital malformations.

4. Awareness of the frequent association with urinary tract malformations (e.g. multicystic dysplastic kidney, unilateral renal dysplasia, single kidney).

Therefore, early diagnostic imaging of the genital or urinary tract should always include both systems. Early imaging in a female also offers the advantage of the usually prominent neonatal genital morphology.

Common indications for the evaluation of the urogenital tract by imaging include known or suspected fetal abnormality, a clinically apparent genital malformation, ambiguous genitalia, cloacal malformation, urogenital sinus, Müllerian duct and vaginal abnormality and congenital adrenal hyperplasia, as well as undescendend testis, congenital inguinal hernia and the various types of congenital hydrocele, cystic dysplasia of the rete testis and cystic-dysplastic seminal vesicles. Disorders of sexual differentiation (intersex) include a wide and complex group of abnormalities resulting from non-accordance between chromosomal, gonadal and genital gender. Due to their complexity and the need for a multidisciplinary team approach, these latter patients should be referred to a dedicated pediatric centre.

Ultrasound including CDS is the primary imaging modality to evaluate both male and female genitalia and urinary tract. Dedicated and expert US technique is essential to obtain adequate diagnostic information (Table 2). In females, a systematic transabdominal and transperineal US approach of the
Table 2 Neonatal female genital US

\begin{tabular}{|c|c|}
\hline \multirow[t]{2}{*}{ Preparation } & Good hydration. \\
\hline & $\begin{array}{l}\text { Full bladder if possible (else consider filling } \\
\text { the bladder with saline using a } 4-\mathrm{F} \text { to } 5-\mathrm{F} \\
\text { catheter.) }\end{array}$ \\
\hline \multirow[t]{3}{*}{ Target anatomy } & Entire genital tract, Entire urinary tract. \\
\hline & Adrenals. \\
\hline & Potentially the distal spinal cord. \\
\hline \multirow[t]{2}{*}{ Transducer } & High-resolution linear. \\
\hline & Additionally consider 3-D transducer. \\
\hline \multirow{2}{*}{$\begin{array}{l}\text { Assessments using } \\
\text { transabdominal } \\
\text { approach }\end{array}$} & $\begin{array}{l}\text { Uterus, cervix, vagina, ovaries: size, } \\
\text { morphology, position, obstruction. }\end{array}$ \\
\hline & $\begin{array}{l}\text { Standard complete assessment of the urinary } \\
\text { tract. }\end{array}$ \\
\hline \multirow[t]{2}{*}{$\begin{array}{l}\text { Assessments using } \\
\text { transperineal approach }\end{array}$} & $\begin{array}{l}\text { Vagina, cervix, urethra, anal canal: position, } \\
\text { patency, filling and emptying. }\end{array}$ \\
\hline & $\begin{array}{l}\text { Level of any obstruction (distance from } \\
\text { obstruction to perineal orifice). }\end{array}$ \\
\hline $\begin{array}{l}\text { Technique for 3-D US } \\
\text { genitography }\end{array}$ & $\begin{array}{l}\text { 3-D acquisition with coronal (thick-slab) } \\
\text { reconstructions may improve the } \\
\text { definition and characterisation of uterine } \\
\text { and/or vaginal abnormalities. }\end{array}$ \\
\hline
\end{tabular}

pelvic cavity with a full or filled bladder is fundamental. Whenever genital US is insufficient for adequate characterization of some uterovaginal abnormality or if vaginal duplication is suspected, a specific sonographic genitography is recommended. It consists of some innocuous fluid (prewarmed saline) instillation into the vagina through a small flexible feeding tube that improves or even allows visualization, particularly of the vagina and cervix (Table 3). Additional rectal saline filling may be useful, e.g. for fistula detection or in Müllerian duct agenesis, assuring the absence of uterus.

Table 3 US-genitography-procedural recommendation

\begin{tabular}{|c|c|}
\hline Indications & $\begin{array}{l}\text { Complementary to standard US for depiction of } \\
\text { malformations. }\end{array}$ \\
\hline \multirow[t]{2}{*}{ Preparation } & Vaginal catheterization under sterile conditions. \\
\hline & $\begin{array}{l}\text { 8-F feeding tube, thinner if urogenital sinus tract; avoid } \\
\text { any air in catheter. }\end{array}$ \\
\hline \multirow[t]{4}{*}{$\begin{array}{l}\text { Infusion } \\
\text { technique }\end{array}$} & $\begin{array}{l}\text { Infuse saline continuously (to compensate for vaginal } \\
\text { leakage). }\end{array}$ \\
\hline & Optimally add US contrast agent to saline. \\
\hline & Additional rectal instillation of saline may be helpful. \\
\hline & $\begin{array}{l}\text { If bladder fails to fill via urogenital sinus, blind bladder } \\
\text { catheterization with second (curved-tip) catheter. }\end{array}$ \\
\hline \multirow{4}{*}{$\begin{array}{l}\text { Scan } \\
\text { technique }\end{array}$} & Combine transabdominal and transperineal approaches. \\
\hline & Include kidneys. \\
\hline & Consider adding 3-D acquisition. \\
\hline & $\begin{array}{l}\text { Proceed with voiding cysto-urethro sonography for } \\
\text { evaluation of vesicoureteral reflux, if needed. }\end{array}$ \\
\hline
\end{tabular}


Table 4 Fluoroscopic genitography-procedural recommendation

Indications

Preparation

Assessment of the bony pelvis

Fluoroscopic technique
Complementary to US for depiction of complex malformations.

For surgical planning.

In same session as US to reuse catheters and reduce invasiveness, or preoperatively.

Vaginal catheterization under sterile conditions.

8-F feeding tube, thinner if urogenital sinus tract, avoid any air in catheter.

Skin markers on perineal external orifices.

Look for spinal/sacral abnormalities.

Water-soluble iodinized contrast medium (100 mg I/ml, or less).

$\mathrm{AP}$ and lateral / oblique spot views.

If bladder fails to opacify via urogenital sinus, blind bladder catheterization with second (curved-tip) catheter.

Proceed with voiding cystourethrography for evaluation of vesicoureteral reflux, if needed.
Subsequent complementary imaging procedures may include fluoroscopic genitography and (ce-)MRI (Table 4, Fig. 1). (T2-) MR-urography may be added for evaluation of associated or combined urinary tract malformations. There are very few indications for a technically dedicated ce-CT (e.g. if no MRI available in complex anatomy for preoperative assessment, such as in cloacal malformations or coexisting orthopedic abnormality involving the pelvis and/or lower spine). Sectional imaging should not be performed as a baseline study but be strictly reserved for selected cases and usually for surgical planning. Notice that, unlike in adults or in older children, MRI evaluation of the genital tract is limited in neonates and infants due to resolution issues and may therefore be less useful. A high-resolution 3-D sequence after saline instillation into the vagina and bladder as well as rectal filling with diluted contrast material may yield more differentiated anatomical information. It is important to remember that imaging evaluation of genital (and also cloacal) malformations is never an emergency procedure. This holds true for almost all complex urogenital malformations in newborns with a normal amount of amniotic fluid, i.e. with normal

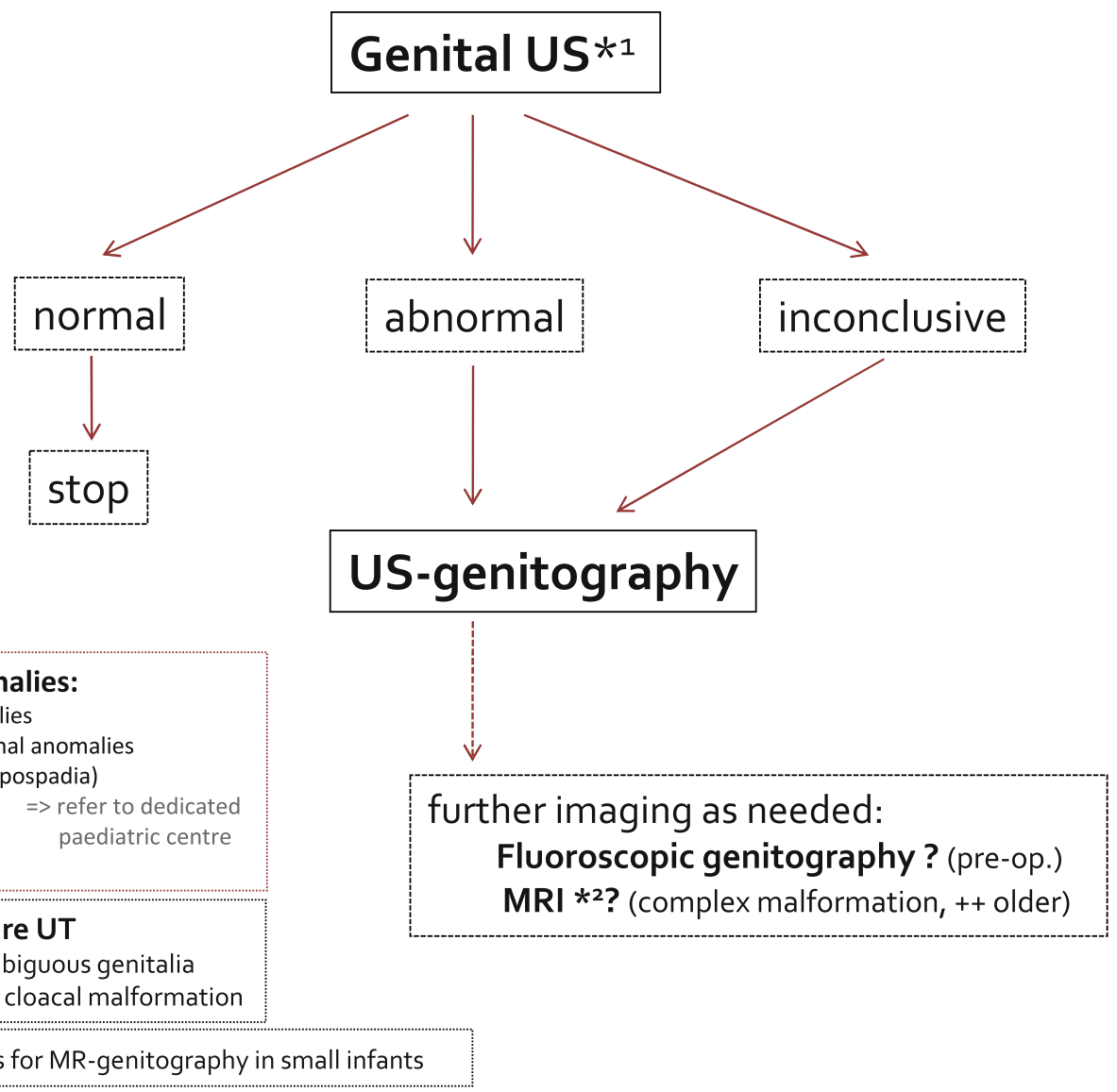

Fig. 1 Imaging algorithm - how to assess the neonatal female genital tract / pelvis legend: proposal on how to approach neonates with suspected genital anomalies. Abbreviations: UT $=$ urinary tract, MRI $=$ Magnetic resonance Imaging, pre-op $=$ pre-operatively, US $=$ ultrasound 
renal function and adequate vital signs. Complex diagnostic imaging should be well prepared and is best performed as an elective study under interdisciplinary cooperation in dedicated centres.

\section{Summary}

Renal biopsy should be performed in children with special precautions and under dedicated conditions to avoid potentially severe complications. The procedure must be standardized. This includes careful pre-interventional preparation with detailed US (including CDS), performance under direct USguidance, use of an optimal core cut needle and a biopsy gun or (semi-)automated biopsy device, prompt tissue evaluation and a thorough post-interventional follow-up (Table 1).

Congenital malformations of the neonatal genital tract are common. Ultrasonography is the first and basic imaging modality and is often diagnostically sufficient (Table 2). Proper US technique complemented by US-genitography may be crucial for a reliable diagnosis (Table 3). Competent US is fundamental in deciding which patients will need complementary imaging with fluoroscopic genitography and/or MRI (Table 4 and Fig. 1), typically reserved for complex malformations and particularly for planning surgical intervention.

Conflict of interest There is no financial or other interest concerning the reported topic.

\section{References}

\section{Renal biopsy}

1. Davis ID, Oehlenschlager W, O'Riordan MA et al (1998) Pediatric renal biopsy: should this procedure be performed in an outpatient setting? Pediatr Nephrol 12:98-100

2. Dodge WF, Daescher CW, Brennan JC et al (1962) Percutaneous renal biopsy in children — general considerations. Pediatrics 30:287-296

3. Feld LG, Stapleton FB, Duffy L (1993) Renal biopsy in children with asymptomatic hematuria or proteinuria: survey of pediatric nephrologists. Pediatr Nephrol 7:441-443

4. Hussain F, Mallik M, Marks SD et al (2010) Renal biopsies in children: current practice and audit of outcomes. Nephrol Dial Transplant 25:485-489

5. Kanzelmeyer NK, Ahlenstiel T, Drube J et al (2010) Protocol biopsydriven interventions after pediatric renal transplantation. Pediatr Transplant 14:1012-1028

6. Memis A, Killi R, Ozer H (1992) Renal arteriovenous fistula after kidney biopsy: colour Doppler ultrasound and angiography diagnosis with embolization using the same procedures. Bildgebung 59:200202

7. Merkus W, Zebregts CJ, Hoitsma AJ et al (1993) High incidence of arteriovenous fistula after biopsy of kidney allografts. Brit J Surg 80: $310-312$
8. Obek SS, Memis A, Killi R et al (1995) Image directed and color Doppler ultrasonography in the diagnosis of postbiopsy arteriovenous fistula of native kidneys. J Clin Ultrasound 23:239-242

9. Printza N, Bosdou J, Pantzaki A et al (2011) Percutaneous ultrasound-guided renal biopsy in children: a single centre experience. Hippokratia 15:258-261

10. Riccabona M, Ring E (1995) Ultrasound guided renal biopsy in childhood-value of Colour Doppler Sonography [Sonographisch gezielte Nierenbiopsie im Kindesalter-Rolle der Farbdopplersonographie]. Wien Klin Wochenschr 107:252-255

11. Riccabona M, Schwinger W, Ring E (1998) Arteriovenous fistula after renal biopsy in children. J Ultrasound Med 17:505-508

12. Riccabona M, Mache CJ, Ring E (2008) Renal biopsy. In: Fotter R (ed) Pediatric uroradiology, 2nd edn. Springer, Berlin-HeidelbergNew York, pp 375-377

13. Riccabona M, Sorantin E, Hausegger K (2002) Imaging guided interventional procedures in paediatric uroradiology - a case based overview. Eur J Radiol 43:167-179

14. Riccabona M (2004) Interventional uroradiology in paediatrics: A potpourri of diagnostic and therapeutic options. Minerva Pediatr 56: $497-505$

\section{Childhood genital imaging}

15. Ahmed SF, AchermannJC AW et al (2011) UK guidance on the initial evaluation of an infant or an adolescent with a suspected disorder of sex development. Clin Endocrinol 75:12-26

16. Chavhan GB, Parra DA, Oudjhane K et al (2008) Imaging of ambiguous genitalia: classification and diagnostic approach. Radiographics 28:1891-1904

17. Garel L, Dubois J, Grignon A et al (2001) US of the pediatric female pelvis: a clinical perspective. Radiographics 21:1393-407

18. Gassner I, Geley TE (2004) Ultrasound of female genital anomalies. Eur Radiol 14:L107-L122

19. Geley TE, Gassner I (2008) Lower urinary tract anomalies of urogenital sinus and female genital anomalies. In: Fotter R (ed) Pediatric uroradiology, 2nd edn. Springer, Berlin-Heidelberg, pp 137-163

20. Adams ME, Hiorns M, Wilcox DT (2006) Combining MDCT, micturating cystography, and excretory urography for 3D imaging of cloacal malformation. AJR Am J Radiol 187:1034-1035

21. Hughes IA, Houk C, Ahmed SF et al (2006) Consensus statement on management on intersex disorders. Arch Dis Child 91:554-563

22. Huisman TAG, van der Hoef M, Willi UV et al (2006) Pre- and postnatal imaging of a girl with a cloacal variant. Pediatr Radiol 36: 991-996

23. Junqueira BLP, Allen LM, Spitzer RF et al (2009) Müllerian duct anomalies and mimics in children and adolescents: correlative intraoperative assessment with clinical imaging. Radiographics 29:10851103

24. Kiechl-Kohlendorfer U, Geley T, Maurer K et al (2011) Uterus didelphys with unilateral vaginal atresia: multicystic dysplastic kidney is the precursor of "renal agenesis" and the key to early diagnosis of this genital anomaly. Pediatr Radiol 41:1112-1116

25. Kiechl-Kohlendorfer U, Geley TE, Unsinn KM et al (2001) Diagnosing neonatal female genital anomalies using salineenhanced sonography. AJR Am J Roentgenol 177:1041-1044

26. Kopač M, Riccabona M, Haim M (2009) Contrast-enhanced voiding Uurosonography and - genitography in a baby with ambiguous genitalia and urogenital sinus [Kontrastverstärkte sonografische Miktionszysto-urethrografie und -genitografie bei einem Kind mit intersexuellem Genitale und Sinus urogenitale]. Ultraschall in Med 30:299-300

27. Lang IM, Babyn P, Oliver GD (1999) MR imaging of paediatric uterovaginal anomalies. Pediatr Radiol 29:163-170 
28. Öçal G (2011) Current concepts in disorders of sexual development. J Clin Res Pediatr Endocrinol 3:105-114

29. Orazi C, Lucchetti MC, Schingo PMS et al (2007) Herlyn-WernerWunderlich syndrome: uterus didelphys, blind hemivagina and ipsilateral renal agenesis. Sonographic and MR findings in 11 cases. Pediatr Radiol 37:657-665

30. Riccabona M (2006) Imaging of the neonatal genito-urinary tract. Eur J Radiol 60:187-198

31. Riccabona M (2011) Potential role of 3DUS in infants and children. Pediatr Radiol 41:S228-237
32. Ehammer T, Riccabona M, Maier E (2011) High resolution MR for evaluation of lower urogenital tract malformations in infants and children: feasibility and preliminary experiences. Eur J Radiol 78: 388-393

33. Wang ZJ, Daldrup-Link H, Coakley FV et al (2010) Ectopic ureter associated with uterine didelphys and obstructed hemivagina: preoperative diagnosis by MRI. Pediatr Radiol 40: $358-360$

34. Ziereisen F, Guissard G, Damry N et al (2005) Sonographic imaging of the paediatric female pelvis. Eur Radiol 15:1296-1309 